\title{
THE NOVEMBER MEETING IN HOUSTON
}

The seven hundred nineteenth meeting of the American Mathematical Society was held at the University of Houston, Houston, Texas, on Saturday, November 23, 1974. There were 147 registrants, including 118 members of the Society.

By invitation of the Committee to Select Hour Speakers for Western Sectional Meetings, there were two one-hour addresses. Professor Seymour V. Parter of the University of Wisconsin spoke on Differential equations with "turning points" and numerical methods; he was introduced by Professor G. R. Blakley. Professor William A. Veech of Rice University addressed the Society on the subject Topological dynamics; the presiding officer at his lecture was Professor Sterling K. Berberian.

By invitation of the same committee there were two special sessions of selected twentyminute papers. Professor E. Ward Cheney of the University of Texas organized a special session on Approximation Theory; the speakers were Bill D. Anderson, Hermann G. Burchard, Charles K. Chui, Philip W. Smith, Arun Kumar Varma, and Daniel E. Wulbert. Professor Richard D. Sinkhorn of the University of Houston organized a special session on Matrix Theory; the speakers were Peter M. Gibson, Darald J. Hartfiel, Emilie V. Haynsworth, Mark Hedrick, Marvin Marcus, William L. Morris, Robert J. Plemmons, and Tom E. Salazar.

There were three sessions of contributed ten-minute papers, for which Professors David G. Bourgin, Raymond T. Hoobler, John S. MacNerney, and Richard A. Tapia served as presiding officers. Of the $\mathbf{2 0}$ ten-minute papers listed in the program, one was presented by title, so that only 19 ten-minute papers were actually presented.

On Friday, November 22, 1974, the day before the meeting itself, the University of Houston sponsored a Symposium on Pure and Applied Mathematics in Memory of Pasquale Porcelli, formerly Professor of Mathematics at Louisiana State University. The speakers at this symposium were Robert M. Brooks, Heron S. Collins, Richard M. Crownover, Richard B. Darst, James R. Dorroh, Ronald G. Douglas, Charles F. Dunkl, John A. Dyer, F. Burton Jones, Kenneth O. Leland, John S. MacNerney, John W. Neuberger, Donald E. Ramirez, James R. Retherford, and Joseph L. Taylor.

URBANA, ILLINOIS

Paul T. Bateman Associate Secretary 